\title{
Jean Tulard
}

\section{Un classique de la Contre-Révolution: les "Considérations sur la France» de Joseph de Maistre}

En 1797, comment ne se serait-on pas interrogé sur le sens des événements que l'on venait de vivre en France. Dix ans auparavant le pays était soumis à un monarque absolu de droit divin; le 21 janvier 1793, la tête de ce souverain était tranchée par le couperet de la guillotine, nouvel instrument de mort qui se substituait à la hache hésitante du bourreau.

Les révolutionnaires s'entretuaient à leur tour: Mirabeau avait dénoncé l'Ancien Régime avant d'être dénoncé par Barnave, lequel était dénoncé par Brissot que dénonçait Desmoulins à son tour dénoncé par Robespierre, lequel d'incorruptible devenait par la grâce de thermidor despote liberticide. Ainsi s'offrait le spectacle d'une Révolution dévorant ses propres enfants comme le sinistre héros de l'enfer de Dante.

Pire: des armées qualifiées de „va-nus-pieds mettaient en échec les Prussiens à Valmy, les Autrichiens à Jemmapes puis à Fleurus, et l'Europe entière coalisée contre une France à feu et à sang, où l'Ouest se soulevait, où Lyon était en partie rasée et Marseille prise d'assaut, cette Europe des rois ne parvenait pas à réduire une poignée de révolutionnaires vociférant et s'envoyant à la guillotine dans une salle inconfortable dite du Manège.

A Paris on mourrait plus ou moins de faim au terme de longues queues aux portes des boulangeries; il n'y avait plus de travail pour l'industrie du luxe, l'assignat s'écroulait, et pourtant la France était encore debout.

Dans un pays où tout événement était jadis salué par un Te Deum, où la pratique religieuse était si forte, deux clergés s'affrontaient, les jureurs d'un côté, les réfractaires de l'autre, devant des églises fermées ou mutilées.

"Je n'y comprends rien*, dit un contemporain. Et il n'est pas le seul. Et comment ne s'interrogerait-on pas sur la façon dont tout cela allait se terminer: on avait cru la Révolution finie au petit matin qui suivit la nuit du $\mathbf{4}$ août, puis lors de la fête de la Fédération, le 14 juillet 1790 , après le 9 thermidor enfin, et chaque fois un nouveau vent de folie a emporté la France.

Rien à espérer des Thermidoriens voués à l'impuissance: ils aspirent à une monarchie constitutionnelle mais n'ont pas de roi sous la main. Rien à attendre du nouveau monarque en exil, Louis XVIII (au fait Louis XVII est-il alors bien mort? se demandent déjà des contemporains) qui dans sa proclamation de Vérone fait preuve d'intransigeance et dont les partisans ratent le débarquement de Quiberon. Un coup de force 
militaire? La Fayette et Dumouriez ont échoué et les têtes de plusieurs généraux (Custine, Houchard) sont tombées pour insubordination ou impéritie.

Quel est donc le sens de cette Révolution? Comment tout cela se terminera-t-il?

Alors, au printemps de 1797, parut un homme qui dans un ouvrage intitulé Considérations sur la France expliqua tout, donnant et le mot de la fin et la fin elle-même. Il avait nom Joseph de Maistre.

Joseph de Maistre n'était pas, ou peu, connu. C'est un Savoyard, non Français mais sujet du roi de Sardaigne. Toutefois le royaume sarde, à cheval sur les Alpes, connaît les mêmes problèmes que son puissant voisin.

Maistre est un bourgeois dont la famille a été récemment anoblie. On pourrait le penser ouvert aux aspirations d'autres bourgeois, ceux qui s'agitent de l'autre côté des Alpes. D'autant qu'il est admis dans une loge maçonnique de Chambéry. Il répond d'ailleurs au duc de Brunswick qui envoie aux Francs-Maçons un questionnaire sur l'origine de la Maçonnerie: "Attachons-nous à l'Evangile et laissons là les folies de Memphis.*

Les débuts de la Révolution l'enchantent, mais l'abolition des droits féodaux le refroidit, la suppression des parlements l'inquiète et l'invasion de la Savoie par les troupes françaises l'oblige à l'exil. La lecture de Burke achève d'en faire un contre-révolutionnaire. En Suisse, il rencontre Gibbon, Mme de Staël et bien d'autres qui l'incitent à se tourner vers la réflexion et l'écriture. Ce seront les lettres d'un royaliste savoisien où se profile la critique des principes révolutionnaires. Une critique incisive mais encore superficielle.

Les Considérations sur la France sont d'un autre poids.

L'œuvre se situe dans la tradition contre-révolutionnaire ouverte par Les réflexions sur la Révolution de Burke. Il y eut ensuite Mallet du Pan avec Les considérations sur la nature de la Révolution de France en 1793 et Bonald qui édite une Théorie du pouvoir politique et religieux dans la société civile en 1796.

Après les Considérations de Maistre viendront les Mémoires pour servir à l'bistoire du Jacobinisme de Barruel.

La littérature contre-révolutionnaire du temps est riche, mais elle est difficile à lire. Burke est terriblement abstrait, même s'il est le plus lisible grâce à des touches personnelles. Barruel serait passionnant s'il n'était terriblement systématique et surtout prolixe.

La supériorité de Maistre? Il est court; il écrit bien; sa démonstration est rigoureuse, même s'il faut accepter l'idée de Dieu pour y entrer.

Maistre répond aux questions que l'on se pose: pourquoi la Révolution? Comment finira-t-elle? 
Pourquoi la Révolution? Incompréhensible, elle l'est certes, mais à l'esprit humain. Elle est donc le fruit de la Providence. Maistre réfute à l'avance la philosophie de l'absurde de Camus et celle du hasard de Monod. Il n'y a point de désordre parce que le désordre est lui-même ordonné par une main souveraine qui "le plie à la règle et le force de concourir au but*.

La Révolution a été décrétée: tout ce qui pourrait la prévenir ou s'y opposer est voué à l'échec. Ceux-là qui croient conduire la Révolution ne sont que les faux démiurges d'une action qu'ils ne contrôlent pas.

C'est l'intervention divine qui peut seule expliquer l'extraordinaire, la chute de la monarchie ou celle de Robespierre, les victoires françaises ou les massacres de septembre.

Mais que veut donc la Providence en dirigeant un ordre qui lui était pourtant favorable? Punir. Punir la France de s'être laissée gagner par les idées pernicieuses des Philosophes. On a bafoué la Divinité en permettant à Voltaire ses blasphèmes. En 1789 l'heure du châtiment a sonné.

Punition effroyable: l'écroulement d'un trône, d'une société, d'une église. Les auteurs de la Révolution en viennent à se châtier eux-mêmes. Le nombre des victimes est proportionnel à l'étendue de la faute. Des innocents ont péri parce que le sacrifice du juste sauve le coupable.

Peut-on espérer une rédemption? Oui, elle s'approche. Comment? Par le rétablissement de la monarchie. Rien n'est plus faux que de croire que ce rétablissement sera l'œuvre d'un consentement préalable des Français. Il se fera par l'entremise d'une poignée d'hommes à la faveur d'un cataclysme provoqué par la Providence. On y trouve déjà Bellart, les Chevaliers de la Foi, les intrigues de Talleyrand et de Fouché.

.Ouvrage étonnant, écrira Sainte-Beuve, où la Révolution est jugée non seulement dans ses principes et dans ses sources, dans toute sa portée et dans son développement, dans ses phases même les plus éloignées où la Restauration future est prédite et presque décrite dans ses voies et moyens.*

Il n'est jamais bon d'avoir raison trop tôt. Les Considérations, dans leur édition de Lausanne comme dans celle de Londres (en réalité Bâle) n'eurent aucun succès en France. Le coup d'Etat du 18 fructidor, déjouant les espoirs d'une restauration monarchique, empêcha leur diffusion. Il fallut attendre l'édition de 1814. On s'émerveilla alors des prédictions de Joseph de Maistre mais comme il passait pour hostile à la Charte il ne reçut aucune récompense.

Par la suite d'autres livres du même auteur, Du Pape ou Les soirées de Saint-Petersbourg, ont éclipsé les Considérations. L'historiographie de la Révolution l'a dédaigné au profit de Burke, de Barruel ou plus récemment de Cochin. On cite rapidement et dédaigneusement Maistre desservi par le caractère surnaturel, métaphysique de ses explications qui fondaient l'école théocratique. 
Joseph de Maistre mourut en 1821, l'année même de la disparition de Napoléon. Faut-il y voir un clin d'œil de la Providence? A vous d'en juger.

\section{Zusammenfassung des Referates von Jean Tulard}

Auch wenn der erste und größte Theoretiker der Gegenrevolution Burke war, so nimmt doch Joseph de Maistre mit seinen 1796 erschienenen Considérations sur la France einen eigenständigen Platz in dieser politischen Strömung ein.

Maistre war bürgerlicher Herkunft und beinahe dreißig, als sein Vater im Alter von 74 Jahren geadelt wurde. Während seiner Studien in Turin wurde er in die Freimaurerei eingeführt.

$\mathrm{Zu}$ Beginn der Revolution begeisterte sich Maistre für die neuen Ideen. Träumte er nicht davon, in den Generalständen aufzutreten?

Die Unterdrückung der Parlamente, die für ihn ein notwendiges Gegengewicht zu den Ausschreitungen des Volkes darstellten, die Invasion Savoyens durch die französischen Truppen, die ihn zwangen, ins Exil zu gehen, und die Lektüre von Burke ließen ihn jedoch zur Gegenrevolution übergehen.

Als Maistre seine Considérations sur la France 1796 veröffentlichte, war er nicht der erste Theoretiker der Gegenrevolution. (Burke war mit seinen Reflections on the Revolution in France der erste.) Er erkannte im Geist von 1789 eine übergroße Neigung zur Abstraktion und zum Individualismus. Der Erfolg seiner Darstellung war derartig, daß Mirabeau versuchte, sie zu widerlegen.

Maistre nahm das Erscheinen einer kleinen Schrift von Benjamin Constant, der für eine gemäßigte Revolution plädierte, zum Vorwand, seine Considérations nicht nur im Geist einer Streitschrift zu verfassen. Sie bestehen aus zwei Teilen: einer allgemeinen Erklärung des Phänomens Revolution und einer Widerlegung Constants.

Wenn ein Ereignis, so erklärt er, der menschlichen Intelligenz unverständlich erscheine, so müsse hierin die Einwirkung der Vorsehung gesehen werden. Maistre weist a priori die Philosophie des Absurden zurück. Der Mensch ist nur in seiner eigenen Sphäre frei, ohne die Möglichkeit, den allgemeinen Plan der Vorsehung zu stören. Gott kann in diese Sphäre durch ein Wunder eingreifen, indem er die materielle und moralische Ordnung, an die der Mensch gewöhnt ist, stört.

Die Revolution ist durch Gott befohlen worden. Sie ist eine Manifestation der Vorsehung. Wie sollte man sonst den Untergang der Monarchie, den Terreur, Valmy oder den 9. Thermidor erklären? Aber weshalb hat der göttliche Wille eine Ordnung, die ihm eigentlich entsprechen mußte, zerstört? Es handelt sich um eine gewollte Strafe Gottes zur Sühne der Gunstbezeigungen, die Könige und Adel (ohne den Klerus zu vergessen) der „secte exécrable“ (der abscheulichen Sekte) der Philosophen gewährt haben. Die Zeit der Vergebung nähere sich jedoch, verkündete Maistre 1796. „Si la Providence efface c'est pour écrire" (Die Vorsehung hat ausgelöscht, um Neues schaffen zu können). 
Die Considérations begründeten die „theokratische“ Schule, deren anderer Repräsentant Bonald war. Die Schrift hatte dennoch keinen großen Erfolg; der Staatsstreich des 18. Fructidor verhinderte die Verbreitung des Werks. Es wurde bis 1814 nicht beachtet; solange, bis man erkannte, daß die Restauration hier durch Maistre in ihrer eigentümlichen Erscheinung vorhergesehen worden war. Aber da man auch eine Kritik der Charte herauslesen konnte, unterdrückte man das Buch. Maistre blieb deshalb um so mehr - nach einem hübschen Wort - „un prophète du passé“ (ein Prophet der Vergangenheit).

\section{Diskussion zum Referat von Jean Tulard}

\section{Leiter: Karl Otmar Frbr. von Aretin}

Den ersten Gesprächspunkt bildete die Einstellung Joseph de Maistres gegenüber dem Ancien Régime. E. Weis glaubte dabei nicht, daß der Autor eine völlige Restauration gewollt habe, besonders nicht eine Restauration der sozialen Einrichtungen von vor 1789. Auf den Kontext des Gesamtwerks de Maistres, in dem die Considérations sur la France nur einen sehr kleinen Teil ausmachten, wies $J$. Tulard hin. Er erklärte, de Maistre sehe in allen Ereignissen die Hand Gottes wirken. 1814 sei de Maistre einer der Theoretiker der Ultraroyalisten geworden. Er habe sich mit jenen, die gegen eine geschriebene Konstitution (folglich also gegen die Charte) und für eine nicht geschriebene, auf der Tradition beruhende „Verfassung“ des Ancien Régime (salisches Recht, Verpflichtung des Königs, die Generalstände zu konsultieren, um neue Steuern zu erheben etc.) gewesen seien, solidarisiert. Tulard führte weiter aus, für de Maistre könne man die Tradition nicht verändern, wie man - nach der Willkür der politischen Veränderungen - eine geschriebene Verfassung ändern oder interpretieren könne. Seit der Revolution hätten sich die Anhänger der Linken auf das Gesetz, die der Rechten auf die Tradition gestützt. Hierzu ergänzte $G$. de Bertier de Sauvigny den Ausspruch de Maistres: „Il serait aussi facile de restaurer l'Ancien Régime que de vider le lac de Genève avec une petite cuillère.“

Eine ganz ähnliche Position wie Burke und de Maistre nahm in Deutschland Novalis ein, der - wie $J$. Clédière ausführte - beide gelesen hatte. Novalis habe die Revolution als Ergebnis eines langen Niedergangsprozesses gesehen, für den die Philosophen des 18. Jahrhunderts verantwortlich gewesen seien und auch Souveräne wie Friedrich II. Sie alle gehörten für Novalis zur Partei Luthers und der Reformation, die die christliche Harmonie, die im Mittelalter geschaffen worden sei, gesprengt hätten.

$\mathrm{Da} \beta$ de Maistre niemals eine Racheposition vertreten habe, darauf wies besonders S. Skalweit hin. So habe dieser zur Besonnenheit geraten, besonders in der Frage der Nationalgüter und bei den Entschädigungen, die den enteigneten Emigranten zukommen sollten. Um Racheaktionen zu vermeiden, habe er eine Lösung in dieser Frage vertreten, die sich vielleicht unter den Emigranten selbst gefunden habe. Wenn auch de Maistre die Revolution als eine Strafe betrachtet habe, so habe er in ihr doch auch in einer Art Dialektik - die Möglichkeit der Regeneration gesehen. Er habe die An- 
sicht vertreten, Ludwig XVIII. dürfe keine Rachemaßnahmen ergreifen, außer im Hinblick auf die Königsmörder. Um diejenigen, mit denen er polemisierte (z. B. Benjamin Constant), wieder zu beruhigen, habe er unaufhörlich seine Opposition gegen jegliche Vergeltung betont. S. Skalweit wies in diesem Zusammenhang auf den Satz am Ende der Considérations hin: „Nous ne voulons pas de contrerévolution mais le contraire de la révolution." $R$. Dufraisse ergänzte hierzu, daß diese Formel als Schlagzeile der ersten Nummer des Berliner politischen Wochenblatts gedient habe, das am 8.Oktober 1831 erschienen sei.

Als einen besonderen Schwachpunkt im Denken von de Maistre erkannte J. Tulard dessen Glauben, eine Gegenrevolution könne ohne Blutvergießen vollzogen werden. Der Augenblick habe ihm zwar 1814 Recht gegeben, da der Wechsel des Regimes sich damals ohne Opfer, lediglich mit einer symbolischen Säuberungsaktion, vollzogen habe. Aus dieser Sicht sei die Rückkehr von Elba eine Katastrophe gewesen, die ein Erwachen des Republikanismus bedeutet habe, das Napoleon übrigens nicht genutzt habe. Das Ergebnis dieser zweiten Restauration sei ein in zwei unverrückbare Lager gespaltenes Frankreich und ein blutiger Beginn gewesen.

Auf die Frage von P. Stadler nach den Gemeinsamkeiten bzw. Unterschieden zwischen de Bonald und de Maistre gab J. Tulard folgende Erklärung: Beide seien aus der „theokratischen“ Schule gekommen, die die Vorsehung ins Zentrum der historischen Entwicklung gestellt habe. Ein Unterschied habe zwischen beiden besonders im Verhalten bestanden. De Bonald sei religiöser und weitschweifiger gewesen, habe aber mit dem Regime Napoleons kollaboriert, während de Maistre nie einen Kompromiß mit dem Lager der Revolution geschlossen habe. Zu Chateaubriand ergänzte Tulard, dessen Konservativismus sei literarischer und brillanter als der von de Maistre gewesen. Chateaubriand wäre außerdem opportunistischer und mehr von Eitelkeit geprägt gewesen; viele Szenen aus Mémoires d'Outre Tombe - wie diejenige des Wiedersehens von Ludwig XVIII., Fouché und Talleyrand - seien Gebilde seiner Phantasie. Tulard wies schließlich auf unterschiedliche Tendenzen im Lager der Ultras hin, die er mit denen zwischen Leninisten und Trotzkisten bei den Marxisten für vergleichbar hielt.

Der letzte Teil der Diskussion richtete sich auf die Problematik einer rationalen Richtung des Konservativismus dieser Zeit in Europa. E. Febrenbach erwähnte in diesem Zusammenhang Friedrich von Gentz, der über die theokratische Schule gespottet habe und schloß daran die Frage an, ob es in Frankreich ein ähnliches Phänomen wie den in Deutschland vieldiskutierten „pragmatischen Staatskonservativismus“ gegeben habe, der nicht mit dem Opportunismus eines Fouché oder eines Talleyrand zu verwechseln sei. Als Vertreter einer solchen Richtung nannte J. Tulard Abbé Dominique Dufour de Pradt (1759-1837), François-Dominique de Reynaud, Comte de Montlosier (1755-1838) und Antoine-François-Claude Comte Ferrand (1751-1825), den Schöpfer der Charte, die die theoretischen Schemata eines de Maistre und Bonald verlassen hätten. Außerdem sei offensichtlich, daß Atheisten der Gedankenwelt eines de Maistre nicht hätten anhängen können. Zu den Pragmatikern zählte $R$. Dufraisse auch Chateaubriand, der die Charte anerkannt habe. Es dürfe nicht vergessen werden - so Dufraisse -, daß vor 1789 die Aristokraten Anhänger einer beschränkten Monarchie gewesen seien. Chateaubriand selbst habe dies mit den Worten ausgedrückt: „Les 
patriciens commencèrent la Révolution, les plébéiens l'achevèrent.“ Nach 1815 wären die Ultraroyalisten die ersten gewesen, die die Bindung von Volk und Monarchie mit der Einführung des allgemeinen Wahlrechts hätten verstärken wollen. Die Revolution habe das heilige Salböl zu Reims durch die Wahlurne ersetzt. Chateaubriand habe das Öl gewollt, um den König zu salben, und die Urne, um das Volk zu befragen. 
